\section{Systems chemistry: logic gates based on the stimuli-responsive gel-sol transition of a crown ether-functionalized bis(urea) gelator $\dagger$}

\author{
Zhenhui Qi, ${ }^{a}$ Paula Malo de Molina, ${ }^{b}$ Wei Jiang, $\dagger^{a}$ Qi Wang, ${ }^{a}$ Karol Nowosinski, ${ }^{a}$ Andrea Schulz, ${ }^{a}$ \\ Michael Gradzielski ${ }^{b}$ and Christoph A. Schalley ${ }^{* a}$
}

\author{
Received 5th December 2011, Accepted 21st March 2012 \\ DOI: $10.1039 / \mathrm{c} 2 \mathrm{sc01018f}$
}

\begin{abstract}
A quite simple, achiral benzo-21-crown-7-substituted bis(urea) low-molecular weight gelator hierarchically assembles into helical fibrils, which further develop into bundles and finally form a stable gel in acetonitrile. The gel-sol transition can be controlled by three different molecular recognition events: $\mathrm{K}^{+}$binding to the crown ethers, pseudorotaxane formation with secondary ammonium ions and $\mathrm{Cl}^{-}$binding to the urea units. Addition of a cryptand that scavenges the $\mathrm{K}^{+}$ions and $\mathrm{Ag}^{+}$addition to remove the chloride and bases/acids, which mediate pseudorotaxane formation, can reverse this process. With the gelator, and these chemical stimuli, a number of different systems can be designed that behave as logic gates. Depending on the choice of components, OR, AND, XOR, NOT, NOR, XNOR and INHIBIT gates have been realized. Thus, the gel-sol transition as a property of the system as a whole is influenced in a complex manner. For some cases, the type of logic gate is defined by input signal concentration so that an even more complex reaction of the gel towards the two input signals is achieved.
\end{abstract}

\section{Introduction}

Until recently, ${ }^{1}$ chemists were educated to synthesize and characterize pure compounds and to investigate them in a very restrictive, well-controlled experimental setup with a strongly reductionistic attitude. However, neither the metabolism of a cell nor many of the functional materials existing nowadays operate in such a reductionistic manner. Understanding the complexity of, for example, the regulation of a cell's metabolism requires a more detailed description on the systems level. An analysis of the network topologies between the many molecules present in a cell and their reactivity relations is at least equally important as knowledge about individual components involved in the network or single reactions between them.

With the introduction of the term "systems chemistry"1,2 in 2005 , a change of paradigm was introduced to chemistry. Systems containing many different components that are interrelated became the focus in quite a number of studies. Different fields of

\footnotetext{
${ }^{a}$ Institut für Chemie und Biochemie, Freie Universität Berlin, Takustrasse 3, 14195 Berlin, Germany. E-mail: christoph@schalley-lab.de; Fax: +49 30-838-55817; Tel: +49 30-838-52639

${ }^{b}$ Institut für Chemie, Sekretariat TC7, Technische Universität Berlin, Strasse des 17. Juni 124, 10623 Berlin, Germany

$\dagger$ Electronic supplementary information (ESI) available: Synthetic procedures and characterization data for new compounds; COSY NMR spectra supporting the NMR signal assignment; additional experiments for the characterization of the gels; ${ }^{1} \mathrm{H}$ NMR experiments supporting the stimuli-responsive behavior. See DOI: 10.1039/c2sc01018f \$ Present Address: The Skaggs Institute for Chemical Biology, The Scripps Research Institute, 10550 N. Torrey Pines Road, La Jolla, California 92037, USA
}

research joined forces and diverse topics were investigated beyond pure molecules - for example, cascading transformations in subcomponent self-assembly, ${ }^{3}$ self-sorting in supramolecular systems, ${ }^{4}$ the adaptive behavior of dynamic combinatorial libraries (DCLs) ${ }^{5}$ or self-replicators that feed on DCLs. ${ }^{6}$ Emergence and self-organization ${ }^{7}$ occurs in chemical systems, when a flow of energy keeps the system away from the thermodynamic minimum and when non-linearity is introduced through autocatalysis. The Belousov-Zhabotinski reaction ${ }^{8}$ is a prominent example of a chemical system in which autocatalysis leads to oscillations between two catalyst redox states. This reaction has been used to affect the viscosity of gels ${ }^{9}$ and to induce directional transport of macroscopic particles on the surfaces of gels. ${ }^{10}$ All of these studies focus on chemical networks, i.e. complex mixtures of interacting components that affect the binding and reactivity of each other. Such networks can be based on covalent or non-covalent bonds between molecules, as realized in dynamic combinatorial chemistry ${ }^{11}$ and self-assembly. ${ }^{12}$ On a more abstract level, they can also be reactivity networks that are best described through a system of differential equations for the formation and consumption of each individual component.

In this contribution, we report the properties of the lowmolecular weight bis(urea) gelator 3 (Fig. 1), which is equipped with two benzo-21-crown-7 moieties. ${ }^{13,14}$ Its sol-gel transition is sensitive to several different chemical signals and can be controlled by complexation of guest ions, such as $\mathrm{K}^{+}$, ammonium ions 5 and $\mathbf{6}$ or the addition of anions, like $\mathrm{Cl}^{-}$. Controlling molecular assembly - in this case, the sol-gel transition - is a prerequisite for designing smart materials. They need to possess selective molecular recognition properties that allow them to 


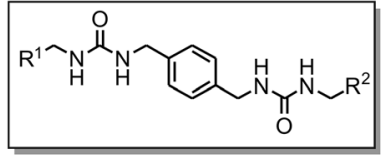

$1 \mathrm{R}^{1}=\mathrm{R}^{2}=$
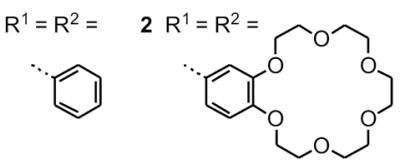

$3 \mathrm{R}^{1}=\mathrm{R}^{2}=$

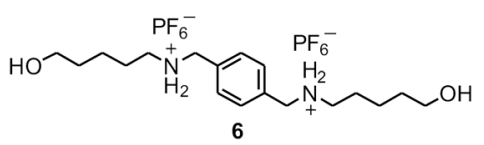

$4 \mathrm{R}^{1}=$
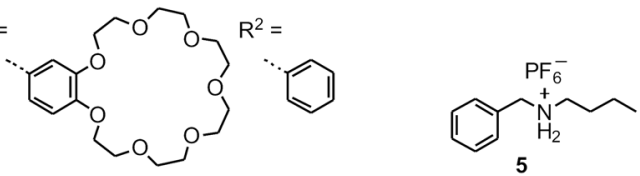

Fig. 1 Molecular structures of bis(urea) derivatives 1-4, and mono- and divalent secondary ammonium axles $\mathbf{5}$ and $\mathbf{6}$.

respond to environmental signals. ${ }^{15}$ In particular, there is a growing interest in endowing supramolecular gels ${ }^{\mathbf{1 6}}$ with stimuli-responsive functionality that could be the basis of smart pharmaceuticals, cosmetics and sensors. ${ }^{17}$ Gelators responsive to light, heat, anions and other changes in the chemical environment have already been reported ${ }^{18}$ Controlling gelation by hostguest interactions, however, still poses a challenge. ${ }^{19}$ Several seminal pieces of research have proven the great potential of introducing macrocyclic cavities in supramolecular gels, ${ }^{20}$ which can be used as a novel way to build-up and break-down supramolecular gel structures to introduce responsive functionality, or to enhance selectivity in applications, such as catalysis. In the present study, we show that systems can be constructed that are comprised of gelator $\mathbf{3}$ and, in addition, several other components. Depending on the selection of these components and thus on the composition of the chemical system, different logic gates ${ }^{21}$ can be constructed in which two chemical input signals are used to control the sol-gel transition. ${ }^{22}$

The benzo-21-crown-7 ether has been chosen for our study not only because crown ethers have been extensively studied as ion binders and molecular scaffolds for materials and biological models in general, ${ }^{23}$ but also because it particularly represents the smallest crown ether capable of forming pseudorotaxanes with secondary dialkylammonium salts that thread through its cavity. ${ }^{24,25}$ This ammonium ion recognition has also been used to construct supramolecular architecture based on the concept of integrative self-sorting. ${ }^{26}$ Thus, a very interesting aspect of benzo-21-crown-7 is that its cavity size is not only small enough for sufficiently strong crown-alkali metal binding, but also large enough for pseudorotaxane formation. Thus, several different inputs can be expected to provide a more complex control of the gelation properties of $\mathbf{3}$ by chemical stimuli.

\section{Results and discussion}

\section{Gelation properties of bis(urea) derivatives 1-4 in different solvents}

When trying to synthesize pseudorotaxanes from the bis-crownsubstituted bis(urea) derivative $\mathbf{3}$, we recognized that this compound forms a gel in acetonitrile (Fig. 2, bottom left). ${ }^{27}$ It starts to form a viscous fluid at a concentration of $0.6 \mathrm{wt} \%$ and the critical gelation concentration (cgc), below which no gel forms, was calculated to be $2.2 \mathrm{wt} \%$. In other solvents, such as methanol, chlorinated organic solvents and acetone, this compound yields partial gels. In contrast, it remains soluble in DMSO after dissolution at higher temperatures, even when cooled back down to room temperature. Several derivatives without crown ether substituents (1), with the smaller 18-crown-6 (2) or unsymmetrically substituted $\mathbf{4}$ were also tested. Surprisingly, 1 failed to form a gel in any of the tested solvents (Fig. 1) and remained insoluble, forming suspensions in most of them. The same is true for 2 , with the exception that it forms a partial gel in acetonitrile. Compound $\mathbf{4}$ also gelates in this solvent. Thus, the bis(urea)-substituted derivative with two smaller benzo-18crown- 6 ethers does not have the same tendency towards gelation as $\mathbf{3}$, but a single benzo-21-crown-7 ether unit in $\mathbf{4}$ is already sufficient to form a stable gel. These observations imply that the presence of the benzo-21-crown-7 moieties is important to promote the gelation process. As gelator 3 showed the best gelation properties in acetonitrile, this gel was selected for a more detailed study.

\section{Hierarchical self-assembly of compound 3 upon gelation in acetonitrile}

Previous studies of linear and cyclic bis(urea) gelators revealed that an antiparallel arrangement of the two urea groups is pivotal for gelation, while a parallel arrangement prevents it. ${ }^{28,29} \mathrm{We}$ assume (Fig. 3a) that this holds true for gelator $\mathbf{3}$ as well based on three arguments besides the analogy to the other bis(urea) gelators. a) The $\mathrm{NH}$-stretch vibration appears at $3318 \mathrm{~cm}^{-1}$ in a chloroform solution, where the urea units form hydrogen bonds with each other. The IR spectrum of the gel of 3 in acetonitrile exhibits this band at $3319 \mathrm{~cm}^{-1}$, indicating that the bifurcated hydrogen bonds between the urea units still exist (ESI†, Fig. S19. b) Calculations nicely show this motif not only to be feasible, but also to result in a helical arrangement, which is experimentally observed in the AFM experiments discussed below. First, a hexadecamer of the core of gelator 3 with the crown ethers omitted was optimized at the semiempirical AM1 level of theory, as implemented in the CaChe program package ${ }^{30}$ (Fig. 3a). The helical arrangement is due to the incommensurability of the urea-urea distance ( $c a .4 .7 \AA$ ) and the optimal phenyl-phenyl stacking distances ( $c a$. $3.7 \AA$ ), which leads to

\begin{tabular}{|c|c|c|c|c|c|}
\hline & solvent & 1 & 2 & 3 & 4 \\
\hline & $\mathrm{CH}_{3} \mathrm{OH}$ & $1^{\mathrm{a}}$ & $1^{\mathrm{a}}$ & $P G$ & $1^{a}$ \\
\hline & $\mathrm{CH}_{2} \mathrm{Cl}_{2}$ & $1^{\mathrm{a}}$ & $1^{\mathrm{a}}$ & $P G$ & $\mathrm{I}^{\mathrm{a}}$ \\
\hline & $\mathrm{CHCl}_{3}$ & $1^{\mathrm{a}}$ & $I^{a}$ & $S(P G)$ & $P G$ \\
\hline & $\mathrm{CH}_{3} \mathrm{CN}$ & $1^{\mathrm{a}}$ & $P G$ & Gel & $\mathrm{Gel}$ \\
\hline & $\left(\mathrm{CH}_{3}\right)_{2} \mathrm{CO}$ & $1^{a}$ & $1^{a}$ & $P G$ & $1^{a}$ \\
\hline & DMSO & $s^{b}$ & $S^{b}(P G)$ & $s^{b}$ & $S^{b}$ \\
\hline$=$ & $\mathrm{H}_{2} \mathrm{O}$ & I & I & I & 1 \\
\hline
\end{tabular}

Fig. 2 Gelation properties of $\mathbf{1 - 4}$ in acetonitrile (2.5 wt $\%)$ : 1: precipitate; 2: partial gel; 3: gel; 4: opaque gel. The table summarizes the gelation properties of 1-4 in different solvents (I: insoluble, $\mathrm{I}^{\mathrm{a}}$ : suspension, $\mathrm{S}$ : clear fluid solution, $\mathrm{S}^{\mathrm{b}}$ : remains clear solution at room temperature after warming to become clear, PG: partial gel (very viscous fluid), Gel: gel). 


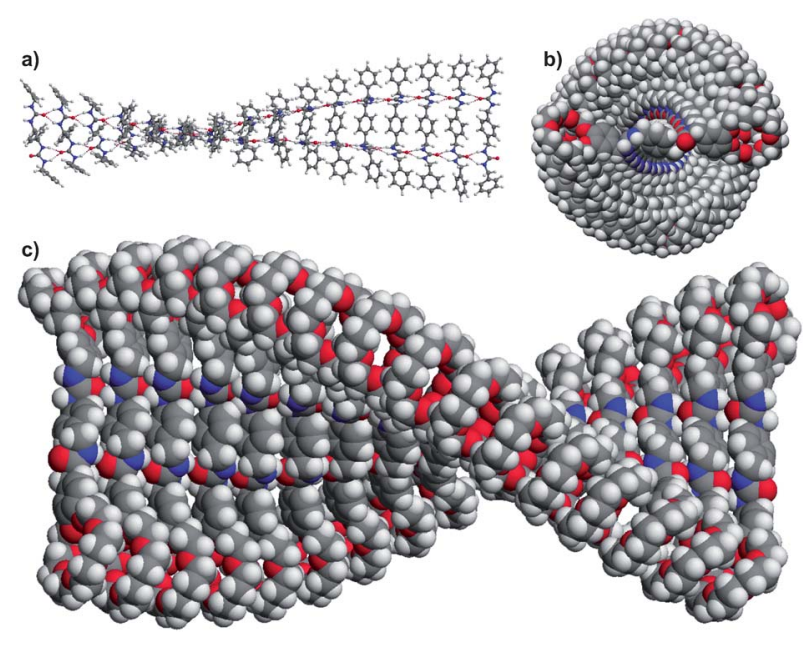

Fig. 3 (a) The core of a hexadecamer of 3 calculated at the AM1 level of theory. Clearly, the bifurcated hydrogen bonding between the urea molecules contributes significantly to the interactions in the stacks of the gelator molecules. (b) Top and (c) side views of an MM3 force-field optimized structure of a complete hexadecamer of 3. Van der Waals interactions between the crowns likely contribute to the stabilization of the stack. The helicity is a result of the urea-urea distances, which do not exactly match the optimal phenyl-phenyl stacking distance and, thus, leads to tilting of the phenyl groups, which induces helix formation.

tilting of phenyl groups relative to the helix axle, which maximizes their mutual interactions. Then, this optimized structure was re-equipped with the 21-crown-7 ethers and the hexadecamer re-optimized with the MM3 force field implemented in the same program (Fig. 3b,c). The crown ethers apparently do not interfere with the helical arrangement of the gelator, but rather increase the Van der Waals interaction surface and thus stabilize the assembly. c) Each urea unit has a dipole moment, which add up along the band through the helix to yield an overall dipole moment along the helix. The anti-parallel arrangement makes sure that the overall dipole moments of the two bands more or less cancel each other out and is energetically more favorable. Thus, the first step in the hierarchical assembly process leads to stacks of the gelators through which two bands of hydrogenbonded urea units run in opposite directions.

Atomic force microscopy (AFM) reveals details of the morphology of the gel-state of 3. In AFM experiments performed with samples of 3 in acetonitrile $(2.5 \mathrm{wt} \%)$ that were spin-coated at $5000 \mathrm{rpm}$ for $20 \mathrm{~min}$. on freshly cleaved mica, networks of long, uniform and straight fibers were observed with fiber lengths of several tens of micrometers (Fig. 4b). This image also reveals the formation of entangled helical coiled-coil fibers with both right-handed $(P)$ - and left-handed $(M)$-helicity. The helices are all more or less linear and only rarely exhibit any kinks or curves. Therefore, they appear to have a quite high flexural rigidity. Helix formation from achiral 3 can be explained by a preference for anisotropic unidirectional growth, ${ }^{31}$ which gives rise to fibrils with long-range chiral order.

Due to the strong overlap of the many fibers in the sample shown in Fig. 4b, section analyses aiming at measuring the diameter or the helical pitch of these fibers are not straightforward. Therefore, a less concentrated sample $\left(0.25 \mathrm{wt}^{\%} \%\right)$ was examined. This concentration is below the critical gel concentration, but analogous fibers are still formed. Spin-coating this sample on mica generated fibers that are well-separated from each other so that height profiles can easily be determined with the AFM tip (Fig. 4c). The section analysis across the thicker helical fibers results in a height of $c a .8 .6 \mathrm{~nm}$ (Fig. 4d). Similar values have been obtained from sections through other fibers (ESI $\dagger$, Fig. S19†). An interesting finding is the observation of thinner fibrils (Fig. 4d), the height of which of $4.2 \mathrm{~nm}$ is close to half that of the thicker fibers and not much larger than the overall length of a stretched-out conformation of a monomer of $\mathbf{3}$. From these experiments, we conclude that achiral monomers of $\mathbf{3}$ first pre-aggregate into hydrogen-bonded dimers or oligomers as small chiral supramolecular units. These units further follow a nucleation-growth pathway ${ }^{31 b}$ and yield fibrils. The thicker fibers - the bundles in Fig. 4a - then form from laterally assembling several of these fibrils, which coil around each other. The diameter of twice that of one fibril suggests that each bundle forms from two or potentially four fibrils. Based on our AFM experiments, it is, however, not possible to clearly distinguish both possibilities. Height profiles along the fibrils reveal a helical pitch of $44-50 \mathrm{~nm}$ for the fibril and of $c a .44 \mathrm{~nm}$ for a bundle (ESI†, Fig. S20). Finally, entanglement of the bundles forms the gel with its small, solvent-immobilizing cavities. Similarly well-defined helical fibers have recently been observed for an n-type perylene bisimide organogelator. ${ }^{32}$

On a macroscopic level, the gel of $\mathbf{3}$ in acetonitrile is characterized by somewhat concentration-dependent gel-sol transition temperatures, $T_{\mathrm{gs}}$, that range from $355 \mathrm{~K}$ for a gelator concentration of $20.8 \mathrm{mM}$ to $367 \mathrm{~K}$ for a $84.0 \mathrm{mM}$ gel (ESI†, Fig. S21). This is in line with differential scanning calorimetric experiments (ESI $\dagger$, Fig. S22), which show evaporation of acetonitrile, but below $353 \mathrm{~K}$ do not show any signal for the gel-sol transition.

\section{Stimuli-responsiveness of the gel obtained from gelator 3 in acetonitrile}

The crown ether substituents can bind cationic guests and, thus, one might expect triggering the gel-sol transition to be possible by the addition of appropriate guest molecules. Potassium ions bind to the benzo-21-crown-7 ether and secondary ammonium ions can slip through their cavities to form pseudorotaxanes. The stimuli-responsive behavior of crown-bis(urea) gel $\mathbf{3}$ was investigated first by adding $\mathrm{KPF}_{6}$. When 1.0 eq. of $\mathrm{K}^{+}$ions was added, the gel phase remained stable, although AFM experiments showed its morphology to undergo significant changes upon cation binding. The fibers get shorter and appear brush-like. Consequently, the addition of 1 eq. of $\mathrm{K}^{+}$mutates the gel into a gel with a different fiber network rather than leaving the original gel unchanged. The gel then starts to collapse upon a progressive addition of more than 1.0 eq. of $\mathrm{K}^{+}$and after the addition of a second equivalent, it was transformed into a homogeneous solution. Subsequent addition of a competitive host for the potassium ions, i.e. the [2.2.2]cryptand, to the sol regenerates the gel. This gel-sol phase transition cycle is shown in Fig. 5 (top row). It can also be followed by ${ }^{1} \mathrm{H}$ NMR spectroscopy (ESI $\dagger$, Fig. S24). While the gel exhibits aggregationbroadened signals, those of the sol are rather sharp. Also, typical signal shifts ${ }^{33}$ occur because of the coordination of the $\mathrm{K}^{+}$ion to the crown ether. After cryptand addition, the initial gel spectrum 
a)
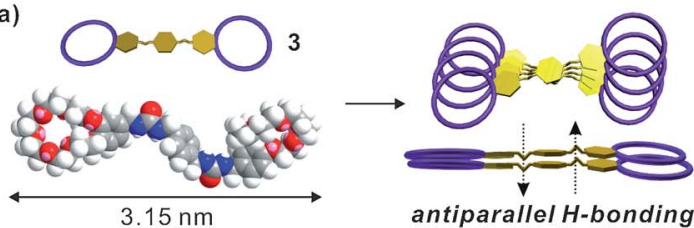

antiparallel H-bonding
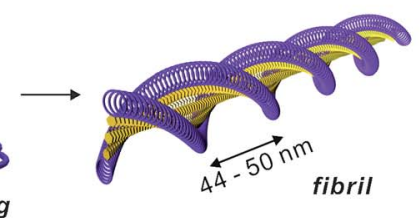

fibril
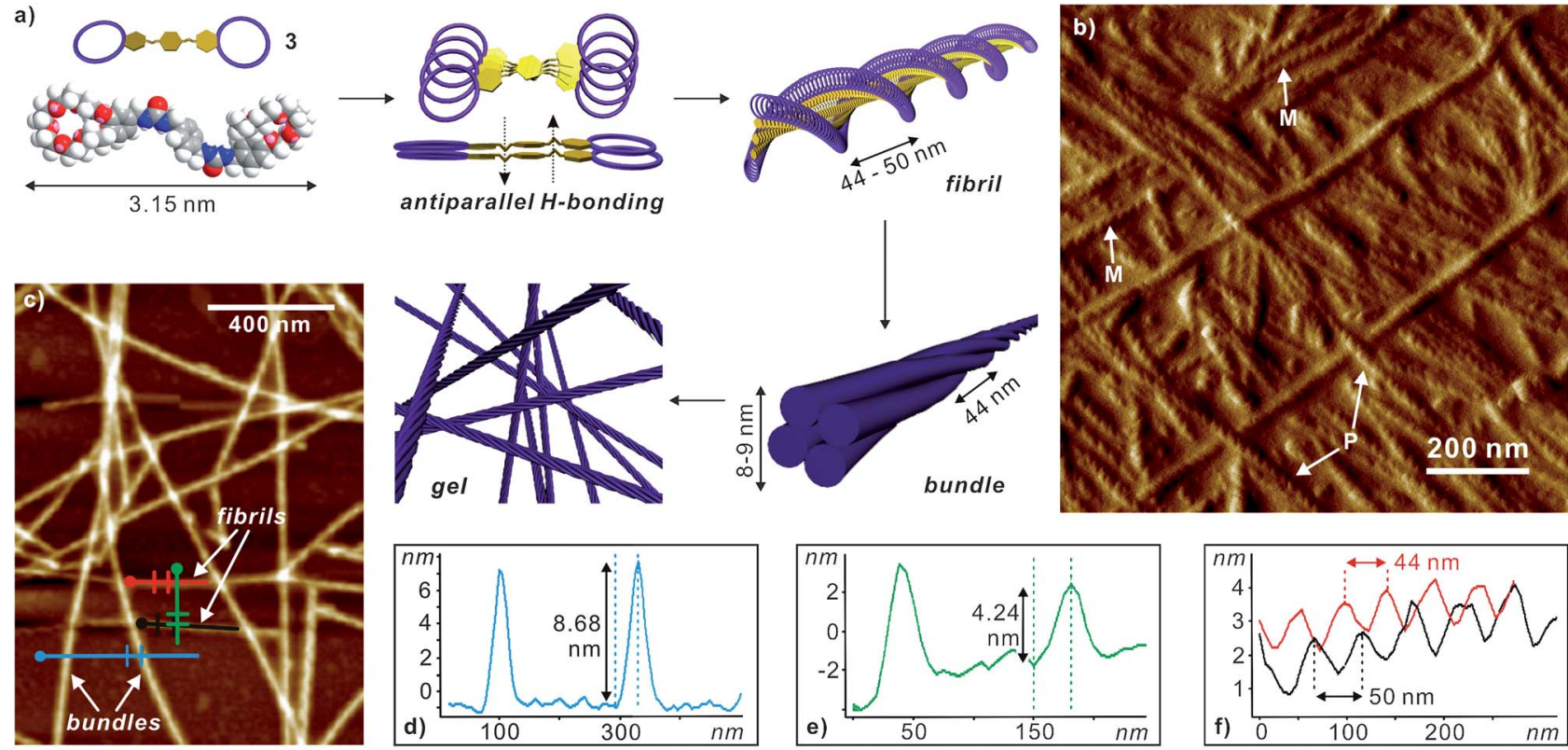

Fig. 4 (a) Gel formation through the hierarchical self-assembly of 3. (b) AFM image (amplitude error, $1 \times 1 \mu \mathrm{m})$ of a solution of 3 in acetonitrile (2.5 wt $\%$ ) spin-coated on freshly cleaved mica and afterwards dried by evaporation of the acetonitrile. Clearly, helical fiber bundles with $(M)$ - and $(P)$-helicity are observed. (c) An AFM height image of a more dilute sample ( $0.25 \mathrm{wt} \%$ ) and height profiles (d) across two bundles of $c a$. $8.6 \mathrm{~nm}$ diameter, (e) across a fibril of ca. $4.2 \mathrm{~nm}$ diameter and (f) along two fibrils with $50 \mathrm{~nm}$ and $44 \mathrm{~nm}$ helical pitch. The positions of these measurements are color-coded in image (c).

is retained. Consequently, occupying almost all crown ethers with $\mathrm{K}^{+}$gives rise to strong charge repulsion, which finally leads to a dissociation of the fibers in the gel. However, since bis(urea) gelators are known to be sensitive to anions that interfere with the urea-urea hydrogen bonding, ${ }^{27 e}$ any interference from the weakly interacting $\mathrm{PF}_{6}{ }^{-}$counterion with gelation must be ruled

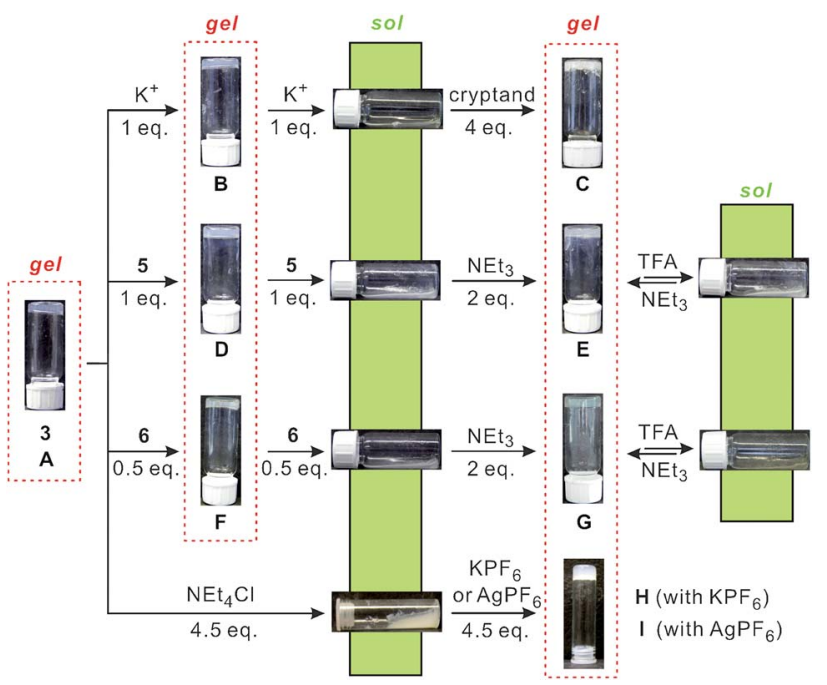

Fig. 5 Photographs of supramolecular gel $3(2.5 \mathrm{wt} \%$ in acetonitrile $)$ and its gel-sol transitions controlled by $\mathrm{K}^{+}$cation binding (top) and the formation of pseudorotaxane structures with mono- and divalent axles $\mathbf{5}$ and 6 (center rows). The two secondary ammonium ions further exhibit reversible acid/base responsiveness. Finally, the addition of chloride triggers a gel-sol transition and can be reversed by precipitation of $\mathrm{KCl}$ or $\mathrm{AgCl}$ (bottom). Letters identify the gels in the rheology section below. out to exclude this anion as the trigger of the gel-sol transition. The experiment was thus repeated with $\mathrm{NEt}_{4} \mathrm{PF}_{6}$. As no gel destruction was observed in this experiment (ESI $\dagger$, Fig. S25), a significant effect of the $\mathrm{PF}_{6}{ }^{-}$anion does not exist and we can conclude that the potassium ion binding to the crown ether triggers the gel-sol transition. Instead of the [2.2.2]cryptand, 18-crown- 6 can also be used to remove the potassium ions and to restore the gel.

Next, the formation of pseudorotaxanes was tested as a stimulus for gel-sol transitions. In analogy to the potassium ions, the addition of one equivalent of monovalent guest 5 to the gel $\mathbf{3}$ did not cause a gel-sol transition. The addition of a second equivalent of 5, however, eventually switches the gel to the sol. Accordingly, complex formation of $\mathbf{5}$ with the crown and the gelsol transition cause considerable changes in the corresponding NMR spectra (Fig. 6, top). Starting with the gel state of $\mathbf{3}$, broad signals are observed (spectrum a), which sharpen significantly and in part shift upon the addition of two equivalents of $\mathbf{5}$ (spectrum b). Once, $\mathbf{5}$ is present in the sample, the sol-gel and gel-sol transitions can be triggered reversibly by the addition of triethylamine (TEA) as a base that deprotonates and thus unthreads 5 from the crown ether and trifluoroacetic acid (TFA), which causes re-protonation and re-threading (spectra c-e). When the same complexation experiments were carried out with dibenzylammonium hexafluorophosphate (Fig. 6, bottom) to $\mathbf{3}$, no gel-sol transition was observed and the gel was maintained. This control experiment not only demonstrates again that the $\mathrm{PF}_{6}{ }^{-}$counterion does not interfere with gel formation. It also clearly shows that pseudorotaxane formation is the reason for the sol-gel transition, when $\mathbf{5}$ is added. The phenyl group is too large to penetrate the benzo-21-crown-7 cavity and thus pseudorotaxane formation is impossible with dibenzylammonium ions. 


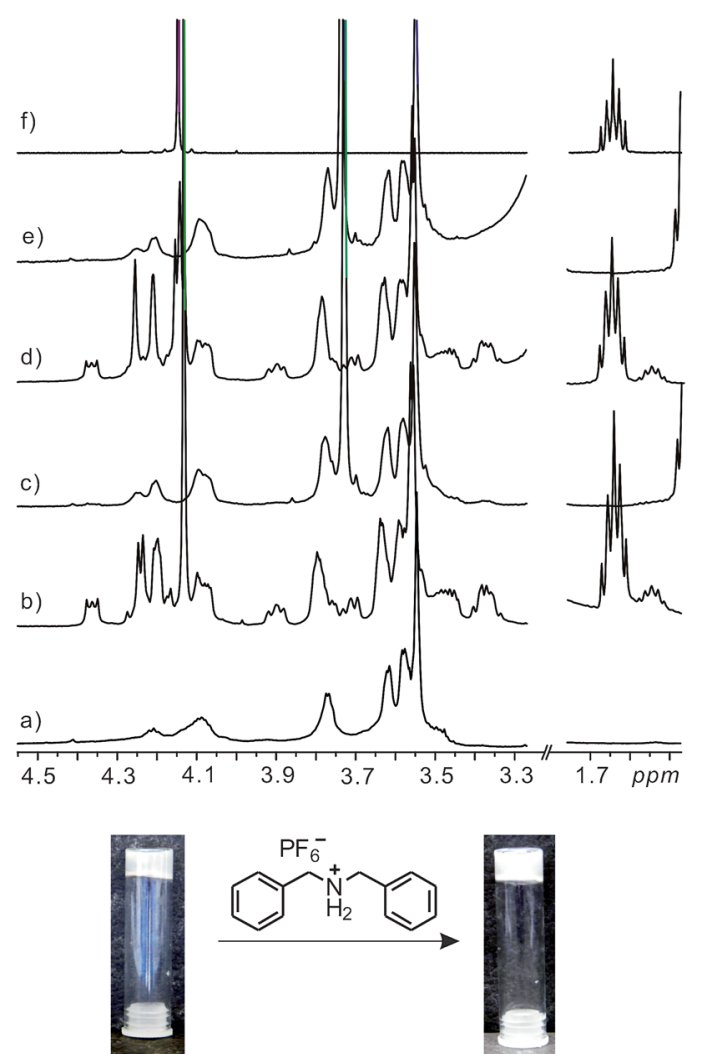

Fig. 6 Top: partial ${ }^{1} \mathrm{H}$ NMR spectra ( $500 \mathrm{MHz}, \mathrm{CD}_{3} \mathrm{CN}, 298 \mathrm{~K}$ ): (a) compound $3(5.2 \mathrm{mM})$ in its gel state. (b) The spectrum obtained after adding 5 (2.0 eq.) to solution (a). Spectra obtained (c) after addition of base (2.2 eq. TEA) to solution (b), (d) after addition of acid (2.0 eq. TFA) to solution (c) and (e) after addition of another 2.0 eq. of base (TEA) to solution (d). (f) Free 5. Bottom: photographs of gelator 3 (20.8 mM in $\mathrm{CH}_{3} \mathrm{CN}$ ) and the mixture obtained after adding 2.0 eq. of dibenzyl ammonium hexafluorophosphate. Since the phenyl group is too large to penetrate the crown ether, no pseudorotaxane forms and the gel persists.

All other potential interaction modes, such as side-on coordination to the crown or hydrogen bond formation with the urea carbonyl oxygen atom, would be possible with both secondary ammonium ions. Consequently, the clear difference in the behavior of the gel towards these two guests indicates that indeed pseudorotaxane formation mediates the gel-sol transition. The same findings were made with divalent guest $\mathbf{6}$, which can thus also be used as a trigger for the gel-sol transition (Fig. 5, third row and ESI†, Figs S27-S29).

Finally, chloride ions were tested as the trigger, since it is known that breaking the urea-urea hydrogen bonding by suitable anions can induce gel-sol transitions. ${ }^{18 b}$ The addition of two equivalents of $\mathrm{NEt}_{4} \mathrm{Cl}$, however, only leads to some shrinking of the gel and leakage of part of the solvent included in the cavities between the gel fibers. If one adds 4.5 equivalents of $\mathrm{NEt}_{4} \mathrm{Cl}$ instead, the gel is converted into a precipitate-containing sol (Fig. 5, bottom). This gel-sol transition can be reversed by the addition of $\mathrm{KPF}_{6}$ or $\mathrm{AgPF}_{6} . \mathrm{KCl}$ or $\mathrm{AgCl}$ precipitate, the $\mathrm{NEt}_{4} \mathrm{PF}_{6}$ side-product does not affect gel formation and, thus, the gel is restored. As the photographs in Fig. 5 show, the product gel obtained at the end of this cycle is more opaque than the starting gel due to the precipitated $\mathrm{KCl}$.

\section{Rheological characterization of the gels}

All gels in Fig. 5 were examined with rheological experiments. Oscillatory measurements were performed with a Malvern (Bohlin) Gemini rheometer employing a plate-plate geometry at a constant temperature of $25^{\circ} \mathrm{C}$ with a fixed deformation of 0.01 , thereby ascertaining to work in the linear viscoelastic regime (see below and Fig. 7d). The two examples shown in Fig. 7a - the native gel $\mathbf{A}$ and sample $\mathbf{I}$ - both show quite constant storage and loss moduli $G^{\prime}$ and $G^{\prime \prime}$. $G^{\prime}$ is significantly larger than $G^{\prime \prime}$, which demonstrates that these gels are dominated by their elastic properties and show the typical behaviour of a Bingham fluid, ${ }^{34}$ which is usually observed for organogels. ${ }^{35}$

Fig. 7b shows the elastic storage modulus $G^{\prime}$ for all samples investigated to be in the range of $1 \times 10^{3}$ to $3 \times 10^{4} \mathrm{~Pa}$ and reveals the conventional increase with increasing frequency for most of the samples. Interestingly, the gels recover their original rheological behavior, even after the addition of salts that induce a gel-sol and a subsequent sol-gel transition, indicating the network structure to be fully recovered after the switching cycle. The elastic properties of the samples after returning to the gel state (C, E, G, $\mathbf{H}$ and $\mathbf{I}$ in Fig. 5) are even more pronounced than for the original gel (except for $\mathbf{E}$, which shows the same value). This increase is not enormous, but clearly visible and indicates that the network formation in these gels is even more effective than in the original structure. This points to a situation where more network points are created in the gel as compared to the situation before the switching cycles. From the elastic modulus one may also estimate an effective number density ${ }^{1} N$ of elastic network points based on the relation $G^{\prime} \approx G_{0}={ }^{1} N \cdot k \cdot T$. From the values given here, one arrives at approximately one network point per $(5.5-16 \mathrm{~nm})^{3}$. This can be considered a rheologically relevant structural size of the elastic network.

Looking at the ratio $G^{\prime} / G^{\prime \prime}$ (Fig. 7c), which is a measure of the relative elasticity of the gel compared to its viscous properties, one finds relatively similar values for all samples that are rather independent of the oscillation frequency. Here, the original gel represents about the upper limit for the observed values. This means that it has relatively the most pronounced elastic properties. For gels $\mathbf{C}, \mathbf{E}, \mathbf{G}, \mathbf{H}$ and $\mathbf{I}$, one finds higher values for $G^{\prime}$, but at the same time they reveal an even more pronounced increase of energy dissipation, as evidenced by the even higher increase of the values of $G^{\prime \prime}$.

Finally, Fig. 7d shows an example of an amplitude scan taken with the samples in order to determine the linear viscoelastic regime. A constant value of the moduli is observed up to a deformation of 0.01 and, accordingly, this deformation was chosen for the oscillatory experiments. However, for deformations higher than 0.01 one observes a significant weakening of the gel properties, i.e., the network is broken up already at rather small deformations.

\section{Construction of logic gates}

With the different reversible inputs available - i.e. alkali cation binding, urea hydrogen bonding to anions and pseudorotaxane formation - and with different ways to reverse these signals - i.e. cation chelation, anion precipitation and the deprotonation of secondary ammonium ions - logic gates can be constructed, 

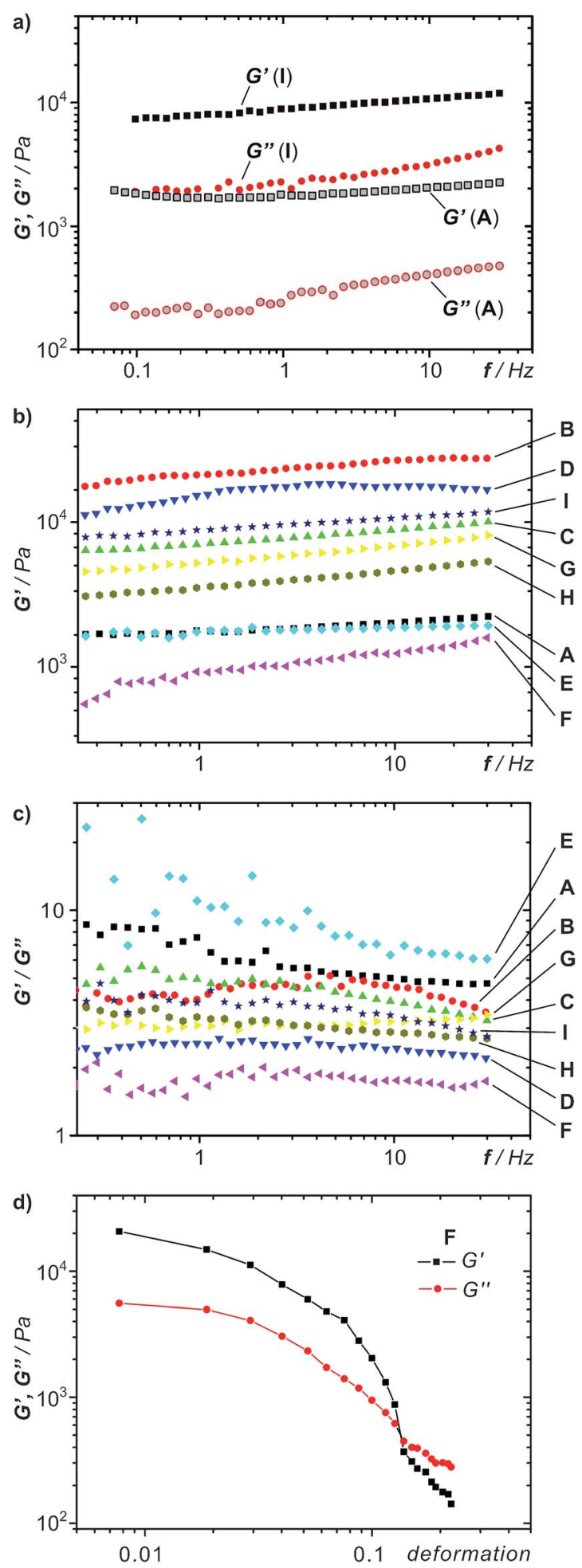

Fig. 7 Rheological characterization of the gels under study. Letters denote the gels as shown in Fig. 5. (a) Storage ( $G^{\prime}$, squares) and loss $\left(G^{\prime \prime}\right.$, circles) modulus as a function of the oscillation frequency $f$ for the native gel A (open symbols) and sample I (full symbols) after the addition of $\mathrm{NEt}_{4} \mathrm{Cl}$ and $\mathrm{AgPF}_{6}$. (b) Elastic storage modulus $G^{\prime}$ as a function of the oscillation frequency $f$ for all samples. (c) The $G^{\prime} / G^{\prime \prime}$ ratio as a function of the oscillation frequency $f$ for all samples. (d) Storage modulus $G^{\prime}$ and loss modulus $G^{\prime \prime}$ as a function of the deformation at a frequency of $1 \mathrm{~Hz}$. which connect two different inputs to the gel-sol or sol-gel transition as the output. Fig. 8 and 9 show the results of experiments aiming at the construction of OR, AND, XOR, NOT, NOR and XNOR gates. Three of them are based on gelator 3 only (Fig. 8). The other three (Fig. 9) use gelator 3 together with suitable additives that extend the range of possible inputs. Two pairs of inputs - the addition of $\mathrm{K}^{+}$and that of $\mathrm{Cl}^{-}$in the XOR gate on one hand and the addition of $\mathrm{K}^{+}$and $\mathrm{Ag}^{+}$in the XNOR gate on the other hand - are interrelated and affect each other.

All gates presented in the following are based on the same output assignment: the gel state corresponds to " 0 ", the sol state to "1". The assignment can be reversed without problems and would, for example, transfer the NOR gate into an OR gate and vice versa. Consequently, the choice of assignment is arbitrary and does not play a crucial role for logic gate construction, but should be and is used consistently in the following to avoid confusion.

The OR gate (Fig. 8a) and the AND gate (Fig. 8b) operate with gelator 3 alone. The starting state is thus a gel (0). Both gates also use the same inputs. Input $\boldsymbol{I}_{\mathbf{1}}$ corresponds to the addition of axle $\mathbf{5}$, input $\boldsymbol{I}_{\mathbf{2}}$ to the addition of $\mathrm{KPF}_{6}$. In order to construct the OR gate, the addition of 2 eq. of either one input is required. Adding 2 eq. of 5 induces the gel-sol transition, as does the addition of 2 eq. of $\mathrm{KPF}_{6}$ and the addition of both. Somewhat higher concentrations of the two inputs still work. In order to obtain an AND gate, the concentration of the two inputs needs to be controlled more precisely. In this case, the addition of 1 eq. of either one compound alone does not trigger the gel-sol transition, but if both add up to a total of 2 eq. of crown etherbinding cations, the sol forms. Consequently, the two gates are closely related to each other and the concentrations of the inputs and thus the signal strength determine which gate is realized. The sequence of signal addition, however, does not cause any differences in the output (the sol) when both inputs are set.

For the XOR gate, it is necessary to find inputs that cancel each other out. Consequently, the addition of $\mathrm{KPF}_{6}$ and $\mathrm{NEt}_{4} \mathrm{Cl}$ comes into play here (Fig. 8c). A single input destroys the gel, be it the $\mathrm{K}^{+}$or the $\mathrm{Cl}^{-}$ion. If, however, both inputs are present, $\mathrm{KCl}$ precipitates and the gel re-forms. As discussed above, the complete destruction of the gel requires 4.5 eq. of chloride. Consequently, the same amount of the potassium salt is necessary for reliable operation of the gate. Again, the sequence of addition of the two signals is not relevant for the final gel state in the $(1,1)$ case. If one reduces the signal strength to two equivalents of chloride and 2 eq. of potassium ions, the shrinking of the gel concomitant with some solvent leakage can be induced and reversed. The XOR gate thus offers again two different switching processes based on the concentration of the stimuli.

For the realization of a NOT gate, the gelator alone is not sufficient. However, when it is mixed with two equivalents of $\mathbf{5}$, a NOT gate can easily be realized by adding and removing protons (Fig. 9a). The starting state is a sol $(\mathrm{O}=1)$. If one adds two equivalents of base $(I=0)$, the secondary ammonium ion is deprotonated and deslips. The gel is restored $(\mathrm{O}=0)$. If one equivalent of acid is added $(\mathrm{I}=1)$, the sol remains a sol. Vice versa, if the gel $(\mathrm{O}=0)$ is treated with one equivalent of acid $(\mathrm{I}=1)$, the secondary amine is re-protonated and the gel destroyed by pseudorotaxane formation $(\mathrm{O}=1)$, while the addition of another equivalent of base $(I=0)$ does not change the gel. 

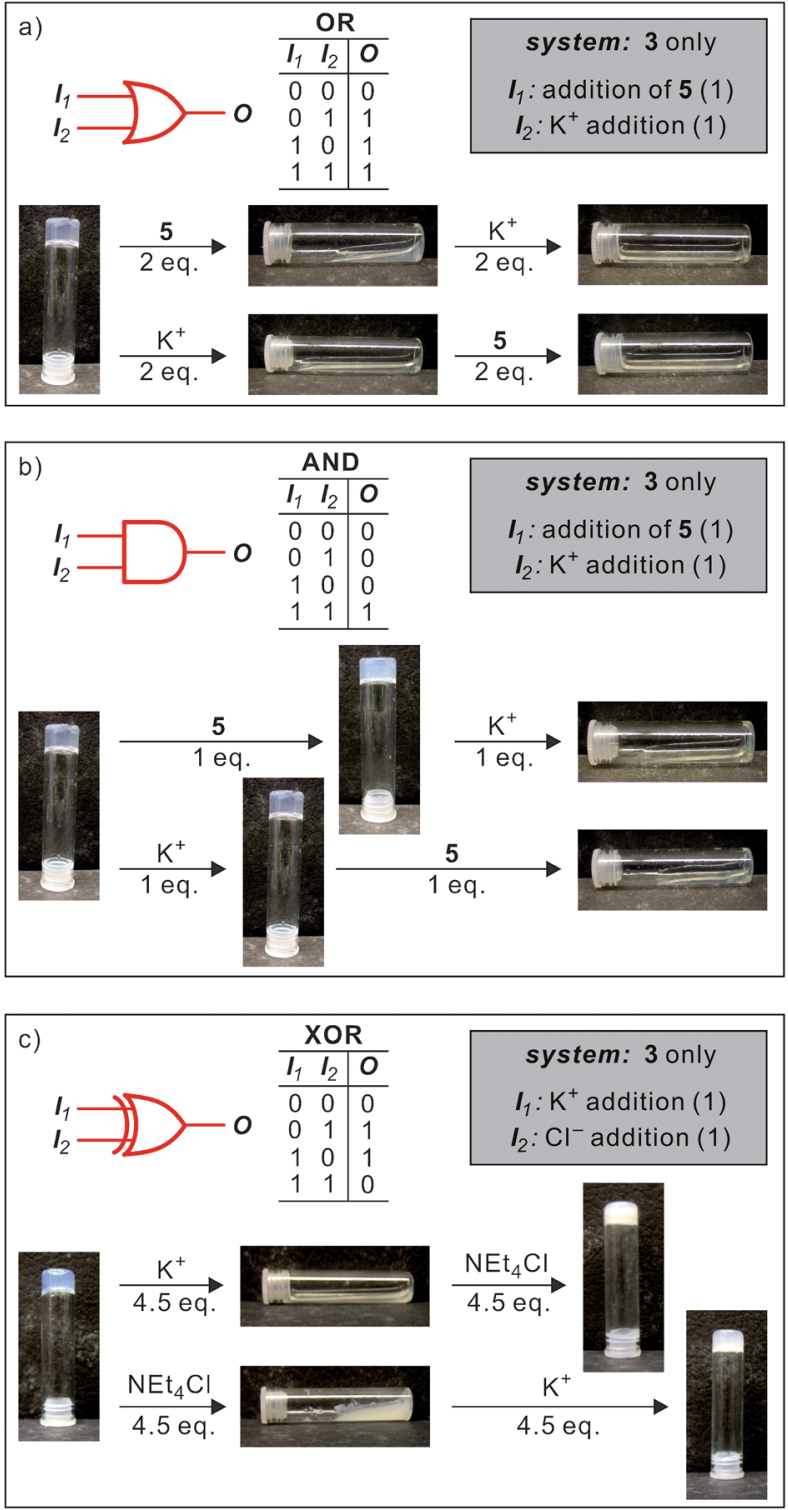

Fig. 8 Three logic gates constructed from gelator 3 alone and two input signals. All gates are based on the same output definition: $\mathrm{Gel}=0, \mathrm{Sol}=$ 1. This assignment is arbitrary and can be reversed. We have chosen this definition, because the gates that are based on the gelator alone then are the simpler ones that do not involve a NOT operation.

The NOR gate (Fig. 9b) requires a mixture of gelator 3 and one equivalent of both, $\mathrm{KPF}_{6}$ and $\mathbf{5}$, as the basis. The two input signals are the [2.2.2]cryptand and triethylamine. The presence of a total of two equivalents of cations present in the starting state breaks the gel and the system exists as a sol initially. The addition of 1 eq. of cryptand or 1 eq. of base or both remove enough of the cation to restore the gel.

As the XOR gate, the XNOR gate (Fig. 9c) requires two interconnected inputs. In this case, the starting state is a sol generated from gelator 3 and 4.5 eq. of $\mathrm{NEt}_{4} \mathrm{Cl}$. Adding the same amount of either $\mathrm{KPF}_{6}$ or $\mathrm{AgPF}_{6}$ removes the chloride by precipitation of the corresponding salt. If both inputs are set, $\mathrm{AgCl}$ has the by far lower solubility and scavenges the chloride anions thus liberating the $\mathrm{K}^{+}$ions in amounts sufficient to
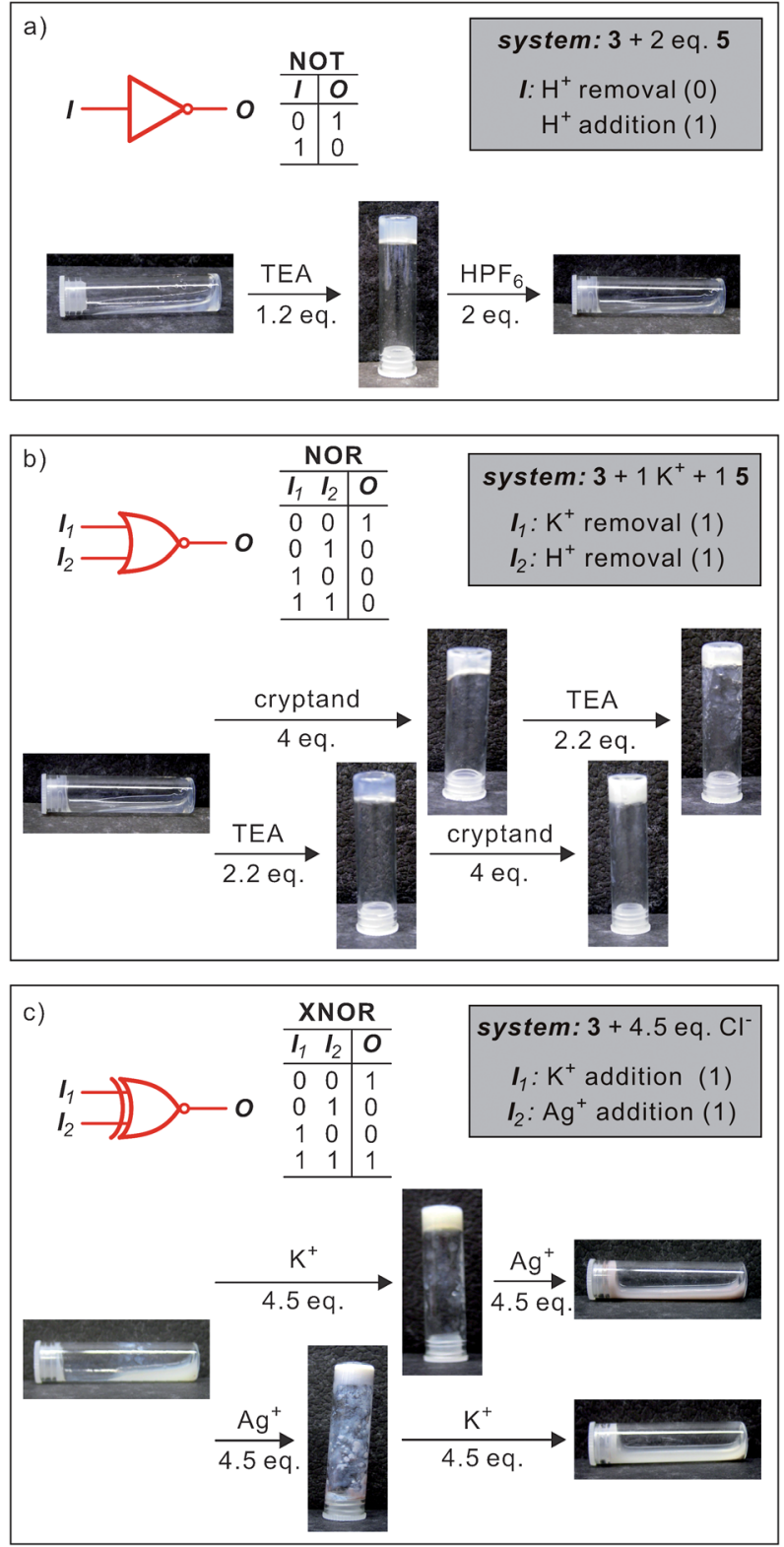

Fig. 9 Three logic gates constructed from gelator $\mathbf{3}$ embedded in (still simple) chemical systems. For consistency, these gates are based on the same output definition as those in Fig. 8: $\mathrm{Gel}=0$, Sol $=1$.

destroy the gel. The sequence of addition is not important indicating that adding the silver salt to a gel containing precipitated $\mathrm{KCl}$ still leads to $\mathrm{AgCl}$ formation and liberation of the potassium ions.

To show that gates with three inputs can also be designed, the INHIBIT gate shown in Fig. 10 was examined. It is based on the AND gate in Fig. $7 \mathrm{~b}$ so that the two inputs $\boldsymbol{I}_{\mathbf{1}}$ and $\boldsymbol{I}_{\mathbf{2}}$ are again the addition of 1 eq. of $\mathrm{KPF}_{6}$ and 1 eq. of 5 . The third prohibitive input signal $\boldsymbol{I}_{3}$ corresponds to 1 eq. of the [2.2.2]cryptand. In the absence of the cryptand, the gate operates as the AND gate in Fig. 8 b. However, when the cryptand is added as the third signal, the output is always the gel state irrespective of the combination of inputs $\boldsymbol{I}_{\mathbf{1}}$ and $\boldsymbol{I}_{\mathbf{2}}$. Thus, the cryptand blocks the operation of the gate converting the simple AND gate into an INHIBIT gate. 


\section{Conclusions}

In conclusion, we have reported a new supramolecular bis(urea) gelator, which bears two crown ethers as molecular recognition units. Three different chemical input signals can be used to switch the gel to a sol: potassium ion binding, pseudorotaxane formation with secondary ammonium ions and hydrogen bond formation to chloride ions. These chemical signals can be reversed by addition of cryptand as a $\mathrm{K}^{+}$scavenger, by acids/bases that switch between the protonation states of the secondary ammonium ion and by addition of $\mathrm{KPF}_{6}$ or $\mathrm{AgPF}_{6}$, which removes the chloride. Thus, these chemical signals can be used to control the material's properties. Rheological experiments show that these gels possess elastic storage moduli in the range of $1 \times 10^{3}$ to $3 \times 10^{4} \mathrm{~Pa}$ and the elasticity is retained after multiple switching. Different logic gates have been constructed on this basis so that the gel-sol transitions can be addressed by one or two input signals that are logically interrelated by OR, AND, XOR, NOT, NOR, XNOR and INHIBIT operations. The system, however, also has some limitations: despite several attempts, no reliably operating NAND gate could be found so far based on gelator 3 and the different input signals described in this article.

When one thinks of logic gates at the molecular level, computers with transistors and memory bits in the nanometer range come to mind, which would be built by a bottom-up approach. Of course, using chemical signals as inputs and gel-sol transitions as outputs for molecular electronics would probably not be a very wise way to realize such a molecular computer. Chemical inputs cause by-products that accumulate during multiple switching processes, although there might be possibilities, such as semi-permeable membranes, that might help to remove them. But furthermore, gel-sol transitions are rather slow so that any computer based on these cannot be expected to be competitive with modern silicon chips. Other aspects, such as the moderate mechanical robustness of the gel or its dimensions

\begin{tabular}{c|cccc|cccc}
\multicolumn{10}{c}{ INHIBIT } \\
\hline $\boldsymbol{I}_{1}$ & 0 & 1 & 0 & 1 & 0 & 1 & 0 & 1 \\
$\boldsymbol{I}_{2}$ & 0 & 0 & 1 & 1 & 0 & 0 & 1 & 1 \\
$\boldsymbol{I}_{3}$ & 0 & 0 & 0 & 0 & 1 & 1 & 1 & 1 \\
\hline $\boldsymbol{O}$ & 0 & 0 & 0 & 1 & 0 & 0 & 0 & 0 \\
\hline
\end{tabular}

system: 3 only
$I_{1}:$ addition of $5(1)$
$I_{2}: \mathrm{K}^{+}$addition (1)
$I_{3}: \mathrm{K}^{+}$removal (1)

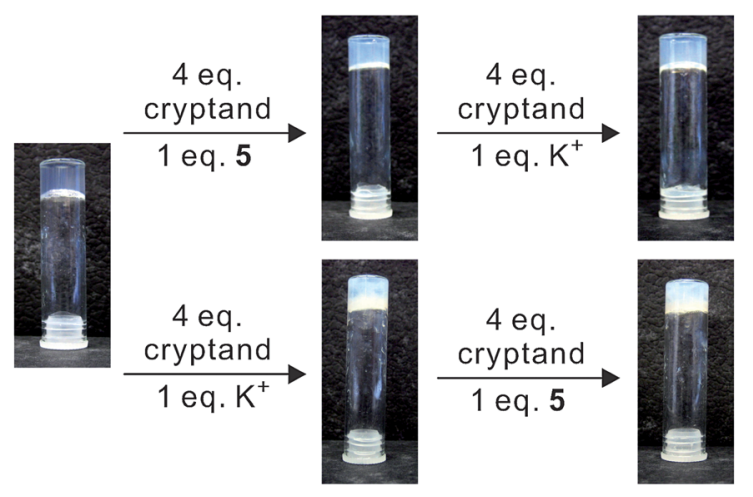

Fig. 10 An INHIBIT gate constructed from gelator 3. In the absence of the inhibiting cryptand signal $\boldsymbol{I}_{3}$, the gate operates as a normal AND gate, as shown in Fig. 8b. In the presence of the cryptand, no gel-sol transition is observed irrespective of the inputs $\boldsymbol{I}_{\mathbf{1}}$ and $\boldsymbol{I}_{\mathbf{2}}$. For consistency: Gel $=0$, Sol $=1$. that are much larger than silicon-based transistors, will also render the development of computers on this basis uninteresting. However, if one thinks of smart materials, such as a gel that loses its load-carrying capability in a triggered gel-sol transition or gels that can be used as tools releasing a drug in the presence of certain chemical stimuli, it may well be advantageous to be able to control the properties of the material with more complex inputs. An AND gate-like behavior, for example, might increase the selectivity for drug release significantly under certain circumstances in that two different signals must be present at the same time. In view of the synthetic nature of our gelator and in particular of the use of acetonitrile as the solvent, the present study certainly represents only a proof-of-principle of such a concept. Nevertheless, a valuable insight is gained into how to trigger gelation and the decomposition of the gel.

A second interesting aspect of the gates presented in this article is that the concentrations of the chemical signals $\mathrm{K}^{+}$and $\mathbf{5}$ decide whether 3 performs as an OR or an AND gate. Similarly, the XOR gate could be fine tuned by the stimuli concentrations between a gel, which merely shrinks and then leaks some of the included solvent, and a complete switching to the sol state. At first glance, this may again appear to be a drawback because the robustness of the gate seems to be compromised. However, a look into nature quickly makes clear that such a feature - different reactions according to the concentrations of a chemical signal - can also be an advantage: when fighting an aggressor, some types of ants use pheromones that attract more soldier ants at high concentration, i.e. close to the location of the combat, in order to be able to forcefully fight back the aggressor. ${ }^{36}$ At lower concentration, i.e. farther away from that place, the same pheromone, however, attracts the ants to a food source and thus helps them to support the colony. In analogy to the ants, different concentrations of a chemical signal cause different behavior of the logic gates described here. The emergence of surprising properties at the system level is a defining feature of complex systems. On a simple level at least, our gates exhibit such a behavior.

Finally, the gelator can be embedded in different - admittedly rather simple - chemical systems. Depending on the choice of components of the system, different logic gates can be constructed from the same gelator. Consequently, a toolbox of components is available, from which the appropriate components can be chosen for different purposes. It is therefore not necessary to develop a new gelator for realizing different logic functions. The same gelator can just be added to the selection of additives that suits the purpose best. With an understanding of more and more complex chemical systems, more and more subtle changes in the materials properties will become available.

\section{Acknowledgements}

We thank the Deutsche Forschungsgemeinschaft (SFB 765 and SCHA 893/5) and the Fonds der Chemischen Industrie for financial support. Z. Q. is grateful to the China Scholarship Council (CSC) for a Ph.D. fellowship.

\section{References}

1 G. von Kiedrowski, S. Otto and P. Herdewijn, J. Syst. Chem., 2010, 1, 1-6. 
2 (a) M. Kindermann, I. Stahl, M. Reimold, W. M. Pankau and G. von Kiedrowski, Angew. Chem., Int. Ed., 2005, 44, 6750-6755. For reviews on systems chemistry, see: (b) R. F. Ludlow and S. Otto, Chem. Soc. Rev., 2008, 37, 101-108; (c) J. J. P. Peyralans and S. Otto, Curr. Opin. Chem. Biol., 2009, 13, 705-713.

3 (a) V. E. Campbell, X. de Hatten, N. Delsuc, B. Kauffmann, I. Huc and J. R. Nitschke, Chem.-Eur. J., 2009, 15, 6138-6142; (b) V. E. Campbell, X. de Hatten, N. Delsuc, B. Kauffmann, I. Huc and J. R. Nitschke, Nat. Chem., 2010, 2, 684-687.

4 M. M. Safont-Sempere, G. Fernández and F. Würthner, Chem. Rev., 2011, 111, 5784-5814

5 (a) Z. Grote, R. Scopelliti and K. Severin, Angew. Chem., Int. Ed., 2003, 42, 3821-3825; (b) K. Severin, Chem.-Eur. J., 2004, 10, 25652580; (c) I. Saur, R. Scopelliti and K. Severin, Chem.-Eur. J., 2006, 12, 1058-1066.

6 V. del Amo and D. Philp, Chem.-Eur. J., 2010, 16, 13304-13318.

7 (a) D. Newth and J. Finnigan, Aust. J. Chem., 2006, 59, 841-848; (b) J. R. Nitschke, Nature, 2009, 462, 736-738.

8 (a) A. N. Zaikin and A. M. Zhabotinsky, Nature, 1970, 225, 535-537; (b) G. Nicolis and J. Portnow, Chem. Rev., 1973, 73, 365-384; (c) I. Prigogine, Science, 1978, 201, 777-785; (d) U. F. Franck, Angew. Chem., Int. Ed. Engl., 1978, 17, 1-15; (e) T. Ueno, K. Bundo, Y. Akagi, T. Sakai and R. Yoshida, Soft Matter, 2010, 6, 6072-6074.

9 (a) T. Ueno, K. Bundo, Y. Akagi, T. Sakai and R. Yoshida, Soft Matter, 2010, 6, 6072-6074; (b) T. Ueno and R. Yoshida, J. Phys. Chem. A, 2011, 115, 5231-5237.

10 R. Yoshida, Adv. Mater., 2010, 22, 3463-3483.

11 (a) J.-M. Lehn and A. V. Eliseev, Science, 2001, 291, 2331-2332; (b) S. Otto, R. L. E. Furlan and J. K. M. Sanders, Science, 2002, 297, 590-593; (c) P. T. Corbett, J. Leclaire, L. Vial, K. R. West, J.-L. Wietor, J. K. M. Sanders and S. Otto, Chem. Rev., 2006, 106, 3652-3711; (d) A. Herrmann, Org. Biomol. Chem., 2009, 7, 3195 3204; (e) R. A. R. Hunt and S. Otto, Chem. Commun., 2011, 47, 847-858; (f) E. Moulin, G. Cormos and N. Giuseppone, Chem. Soc. Rev., 2012, 41, 1031-1049.

12 (a) D. Philp and J.-F. Stoddart, Angew. Chem., Int. Ed. Engl., 1996, 35, 1154-1196; (b) J.-M. Lehn, Science, 2002, 295, 2400-2403; (c) G. M. Whitesides and M. Boncheva, Proc. Natl. Acad. Sci. U. S. A., 2002, 99, 4769-4774; (d) K. Ariga, J. P. Hill, M. V. Lee, A. Vinu, R. Charvet and S. Acharya, Sci. Technol. Adv. Mater., 2008, 9, 014109.

13 For examples of gelators bearing crown ethers, see: (a) J. H. Jung, Y. Ono, K. Sakurai, M. Sano and S. Shinkai, J. Am. Chem. Soc, 2000, 122, 8648-8653; (b) T. Oku, Y. Furusho and T. Takata, Angew. Chem., Int. Ed., 2004, 43, 966-969; (c) Z. Ge, J. Hu, F. Huang and S. Liu, Angew. Chem., Int. Ed., 2009, 48, 1798-1802; (d) S.-Y. Hsueh, C.-T. Kuo, T.-W. Lu, C.-C. Lai, Y.-H. Liu, H.-F. Hsu, S.-M. Peng, C.-h. Chen and S.-H. Chiu, Angew. Chem., Int. Ed., 2010, 49, 9170-9173; (e) S. Dong, Y. Luo, X. Yan, B. Zheng, X. Ding, Y. Yu, Z. Ma, Q. Zhao and F. Huang, Angew. Chem., Int. Ed., 2011, 50, 1905-1909; (f) Y. Kohsaka, K. Nakazono, Y. Koyama, S. Asai and T. Takata, Angew. Chem., Int. Ed., 2011, 50, 4872-4875; (g) A. A. Sobczuk, S.-i. Tamaru and S. Shinkai, Chem. Commun., 2011, 47, 3093-3095; (h) Y.-S. Su, J.-W. Liu, Y. Jiang and C.-F. Chen, Chem. Eur. J., 2011, 17, 2435 2441.

14 For a few general reviews on supramolecular polymers, see: $(a)$ ed. A Ciferri, Supramolecular Polymers, Marcel Dekker, New York 2000; (b) L. Brunsveld, B. J. B. Folmer, E. W. Meijer and R. P. Sijbesma, Chem. Rev., 2001, 101, 4071-4097; (c) L. Bouteiller, Adv. Polym. Sci., 2007, 79-112.

15 G. M. Whitesides and B. Grzybowski, Science, 2002, 295, 2418-2421.

16 (a) N. M. Sangeetha and U. Maitra, Chem. Soc. Rev., 2005, 34, $821-$ 836; (b) R. G. Weiss, Acc. Chem. Res., 2006, 39, 489-497; (c) P. Dastidar, Chem. Soc. Rev., 2008, 37, 2699-2715.

17 A. R. Hirst, B. Escuder, J. F. Miravet and D. K. Smith, Angew. Chem., Int. Ed., 2008, 47, 8002-8018.

18 (a) T. Ogoshi, Y. Takashima, H. Yamaguchi and A. Harada, J. Am. Chem. Soc., 2007, 129, 4878-4879; (b) H. Maeda, Chem.-Eur. J., 2008, 14, 11274-11282; (c) D. D. Díaz, J. J. Cid, P. Vázquez and T. Torres, Chem.-Eur. J., 2008, 14, 9261-9273; (d) G. O. Lloyd and J. W. Steed, Nat. Chem., 2009, 1, 437-442; (e) J. H. Kim, M. Seo, Y. J. Kim and S. Y. Kim, Langmuir, 2009, 25, 1761-1766; (f) T. Tazawa, S. Yagai, Y. Kikkawa, T. Karatsu, A. Kitamura and A. Ajayaghosh, Chem. Commun., 2010, 46, 1076-1078; $(g)$
X. Wang, L. Zhou, H. Wang, Q. Luo, J. Xu and J. Liu, J. Colloid Interface Sci., 2011, 353, 412-419; $(h)$ F. Rodriguez-Llansola, J. F. Miravet and B. Escuder, Chem. Commun., 2011, 47, 47064708; (i) V. Lozano, R. Hernandez, A. Arda, J. Jimenez-Barbero, C. Mijangos and M.-J. Perez-Perez, J. Mater. Chem., 2011, 21, $8862-8870$.

19 (a) J. A. Foster and J. W. Steed, Angew. Chem., Int. Ed., 2010, 49, 6718-6724; (b) Y. Suzaki, T. Taira and K. Osakada, J. Mater. Chem., 2011, 21, 930-938.

20 (a) I. Hwang, W. S. Jeon, H.-J. Kim, D. Kim, H. Kim, N. Selvapalam, N. Fujita, S. Shinkai and K. Kim, Angew. Chem., Int. Ed., 2007, 46, 210-213; (b) X. Liao, G. Chen, X. Liu, W. Chen, F. Chen and M. Jiang, Angew. Chem., Int. Ed., 2010, 49, 4409-4413; (c) B. Verdejo, F. Rodriguez-Llansola, B. Escuder, J. F. Miravet and P. Ballester, Chem. Commun., 2011, 47, 2017-2019.

21 Several other approaches to molecule-level logic gates have been described. For a few recent examples, see: (a) H. Komatsu, S. Matsumoto, S. Tamaru, K. Kaneko, M. Ikeda and I. Hamachi, J. Am. Chem. Soc., 2009, 131, 5580-5585; (b) N. Wagner and G. Ashkenasy, Chem.-Eur. J., 2009, 15, 1765-1775; (c) G. Ashkenazy, Z. Dadon, S. Alesebi, N. Wagner and N. Ashkenazy, Isr. J. Chem., 2011, 51, 106-177 (peptide networks); (d) W. Jiang, M. Han, H.-Y. Zhang, Z.-J. Zhang and Y. Liu, Chem.-Eur. J., 2009, 15, 9938-9945; (e) X. Ma and H. Tian, Chem. Soc. Rev., 2010, 39, 70-80; (fluorescent and charge-transfer rotaxanes); $(f)$ E. H. Witlicki, C. Johnsen, S. W. Hansen, D. W. Silverstein, V. J. Bottomley, J. O. Jeppesen, E. W. Wong, L. Jensen and A. H. Flood, J. Am. Chem. Soc., 2011, 133, 72887291 (plasmonic devices); ( $g$ ) A. Saghatelian, N. H. Völcker, K. M. Guckian, V. S.-Y. Lin and M. R. Ghadiri, J. Am. Chem. Soc., 2003, 125, 346-347 (DNA-based photonic gates); $(h)$ A. Coskun, E. Deniz and E. U. Akkaya, Org. Lett., 2005, 7, 51875189 (half-subtractor based on BODIPY dyes). For reviews, see; $(i)$ A. P. de Silva and N. D. McClenaghan, Chem.-Eur. J., 2004, 10, 574-586; (j) F. M. Raymo, Adv. Mater., 2002, 14, 401-414; $(k)$ I. K. Cheah, S. J. Langford and M. J. Latter, Supramol. Chem., 2005, 17, 121-128; (l) A. P. de Silva, D. P. Fox, A. J. M. Huxley and T. S. Moody, Coord. Chem. Rev., 2000, 205, 41-57.

22 H. Komatsu, S. Matsumoto, S.-I. Tamaru, K. Kaneko, M. Ikeda and I. Hamachi, J. Am. Chem. Soc., 2009, 131, 5580-5585.

23 G. W. Gokel, W. M. Leevy and M. E. Weber, Chem. Rev., 2004, 104, 2723-2750.

24 The recent discovery that benzo-21-crown-7 is large enough for secondary ammonium ions to thread through its cavity was reported by Huang et al. (a) C. Zhang, S. Li, J. Zhang, K. Zhu, N. Li and F. Huang, Org. Lett., 2007, 9, 5553-5556; (b) C. Zhang, K. Zhu, S. Li, J. Zhang, F. Wang, M. Liu, N. Li and F. Huang, Tetrahedron Lett., 2008, 49, 6917-6920; (c) X. Yan, M. Zhou, J. Chen, X. Chi, S. Dong, M. Zhang, X. Ding, Y. Yu, S. Shao and F. Huang, Chem. Commun., 2011, 47, 7086-7088.

25 For examples of secondary ammonium/crown pseudorotaxanes, see: (a) P. R. Ashton, P. J. Campbell, P. T. Glink, D. Philp, N. Spencer, J. F. Stoddart, E. J. T. Chrystal, S. Menzer, D. J. Williams and P. A. Tasker, Angew. Chem., Int. Ed., 1995, 34, 1865-1869; (b) M.-V. Martínez-Díaz, N. Spencer and J. F. Stoddart, Angew. Chem., Int. Ed. Engl., 1997, 36, 1904-1907; (c) P. R. Ashton, I. Baxter, M. C. T. Fyfe, F. M. Raymo, N. Spencer, J. F. Stoddart, A. J. P. White and D. J. Williams, J. Am. Chem. Soc., 1998, 120, 2297-2307; (d) A. G. Kolchinski, R. A. Roesner, D. H. Busch and N. W. Alcock, Chem. Commun., 1998, 1437-1438; (e) N. Yamaguchi, L. M. Hamilton and H. W. Gibson, Angew. Chem., Int. Ed., 1998, 37, 3275-3279; $(f)$ D. Fitzmaurice, S. N. Rao, J. A. Preece, J. F. Stoddart, S. Wenger and N. Zaccheroni, Angew. Chem., Int. Ed., 1999, 38, 1147-1150; (g) P. T. Glink, A. I. Oliva, J. F. Stoddart, A. J. P. White and D. J. Williams, Angew. Chem., Int. Ed., 2001, 40, 1870-1875; (h) T. Clifford, A. Abushamleh and D. H. Busch, Proc. Natl. Acad. Sci. U. S. A., 2002, 99, 4830-4836; (i) H. W. Gibson, N. Yamaguchi, L. Hamilton and J. W. Jones, J. Am. Chem. Soc., 2002, 124, 4653-4665; (j) H. W. Gibson, N. Yamaguchi and J. W. Jones, J. Am. Chem. Soc., 2003, 125, 3522-3533; $(k)$ F. Huang and H. W. Gibson, Prog. Polym. Sci., 2005, 30, 982-1018; (l) E. R. Kay, D. A. Leigh and F. Zerbetto, Angew. Chem., Int. Ed., 2007, 46, 72-191; (m) F. Wang, C. Han, C. He, Q. Zhou, J. Zhang, C. Wang, N. Li and F. Huang, J. Am. Chem. Soc., 2008, 130, 11254-11255; (n) Z. Ge, J. Hu, F. Huang 
and S. Liu, Angew. Chem., Int. Ed., 2009, 48, 1798-1802; (o) S. Dong, Y. Luo, X. Yan, B. Zheng, X. Ding, Y. Yu, Z. Ma, Q. Zhao and F. Huang, Angew. Chem., Int. Ed., 2011, 50, 1905-1909. For reviews, see: $(p)$ T. J. Hubin and D. H. Busch, Coord. Chem. Rev., 2000, 200-202, 5-52; $(q)$ B. Zheng, F. Wang, S. Dong and F. Huang, Chem. Soc. Rev., 2012, 41, 1621-1636.

26 (a) W. Jiang, H. D. F. Winkler and C. A. Schalley, J. Am. Chem. Soc., 2008, 130, 13852-13853; (b) W. Jiang and C. A. Schalley, Proc. Natl. Acad. Sci. U. S. A., 2009, 106, 10425-10429; (c) W. Jiang, A. Schäfer, P. C. Mohr and C. A. Schalley, J. Am. Chem. Soc., 2010, 132, 23092320; (d) W. Jiang, D. Sattler, K. Rissanen and C. A. Schalley, Org. Lett., 2011, 13, 4502-4505.

27 For selected references reporting bis(urea) gelators that are not substituted with crown ethers, see: (a) J. van Esch, S. De Feyter, R. M. Kellogg, F. De Schryver and B. L. Feringa, Chem.-Eur. J., 1997, 3, 1238-1243; (b) F. S. Schoonbeek, J. H. van Esch, R. Hulst, R. M. Kellogg and B. L. Feringa, Chem.-Eur. J., 2000, 6, 26332643; (c) Y. Jeong, K. Hanabusa, H. Masunaga, I. Akiba, K. Miyoshi, S. Sakurai and K. Sakurai, Langmuir, 2005, 21, 586594; (d) C. Wang, D. Zhang and D. Zhu, Langmuir, 2006, 23, 14781482; (e) J. W. Steed, Chem. Soc. Rev., 2010, 39, 3686-3699.

28 (a) J. H. van Esch, F. Schoonbeek, M. de Loos, H. Kooijman, A. L. Spek, R. M. Kellogg and B. L. Feringa, Chem.-Eur. J., 1999, 5, 937-950; (b) M.-O. M. Piepenbrock, G. O. Lloyd, N. Clarke and J. W. Steed, Chem. Commun., 2008, 2644-2646.

29 For examples of studies of supramolecular polymers of bis(urea) compounds, see: (a) A. Arnaud and L. Bouteiller, Langmuir, 2004,
20, 6858-6863; (b) L. Bouteiller, O. Colombani, F. Lortie and P. Terech, J. Am. Chem. Soc., 2005, 127, 8893-8898; (c) M. Bellot and L. Bouteiller, Langmuir, 2008, 24, 14176-14182.

30 Cache 5.0 program package, Fujitsu Inc., Krakow, Poland.

31 (a) A. Brizard, R. Oda and I. Huc, Top. Curr. Chem., 2005, 256, 814 824; (b) P. Jonkheijm, P. van der Schoot, A. P. H. J. Schenning and E. W. Meijer, Science, 2006, 313, 80-83; (c) A. R. A. Palmans and E. W. Meijer, Angew. Chem., Int. Ed., 2007, 46, 8948-8968; (d) D. Pijper and B. L. Feringa, Soft Matter, 2008, 4, 1349-1372; (e) J. Crusats, Z. El-Hachemi and J. M. Ribo, Chem. Soc. Rev., 2010, 39, 569-577.

32 X.-Q. Li, V. Stepanenko, Z. Chen, P. Prins, L. D. A. Siebbeles and F. Würthner, Chem. Commun., 2006, 3871-3873.

33 W. Jiang and C. A. Schalley, Beilstein J. Org. Chem., 2010, 6, no. 14.

34 (a) E. C. Bingham, Fluidity and Plasticity, McGraw-Hill, New York, 1922; (b) J. D. Ferry, Viscoelastic Properties of Polymers, Wiley, New York, 1980.

35 (a) P. L. Luisi, R. Scartazzini, G. Haering and P. Schurtenberger, Colloid Polym. Sci., 1990, 268, 356-374; (b) C. M. Garner, P. Terech, J.-J. Allegraud, B. Mistrot, P. Nguyen, A. de Geyer and D. Rivera, J. Chem. Soc., Faraday Trans., 1998, 94, 2173-2179; (c) P. Terech, D. Pasquier, V. Bordas and C. Rossat, Langmuir, 2000, 16, 4485-4494; (d) M. Burkhardt, S. Kinzel and M. Gradzielski, J. Colloid Interface Sci., 2009, 331, 514-521.

36 B. Hölldobler and E. O. Wilson, The Superorganism: The Beauty, Elegance, and Strangeness of Insect Societies, W. W. Norton \& Co., New York, 2009. 